\title{
É necessário integrar as crianças à sociedade?
}

\section{Is it necessary to integrate children into society?}

Lisandra Ogg Gomes, Doutora em Educação pela USP, mestre e especialista em Educação pela UFPR e graduada em Ciências Econômicas pela UFPR.

Contato: lisandraogg@yahoo.com.br

\section{Resumo}

0 propósito deste texto é refletir sobre a participação das crianças na sociedade, pois se considera que a infância ainda ocupa uma posição secundária no amplo debate social. As pesquisas e as propostas políticas costumam tratálas a partir de suas famílias ou inseridas nas instituições escolares. Assim sendo, é central considerar o significado e a importância da infância para a sociedade a fim de produzir outros olhares e práticas sociais, políticas e econômicas vinculadas às crianças, uma vez que essa categoria geracional é basilar para o desenvolvimento da sociedade. Palavras-chave: crianças; infância; sociedade.

\begin{abstract}
The aim of this paper is to think about children's participation in the society whereas childhood still has a subordinate position in the broad social discussion. The researches and politics proposals often consider children within the family or the school. Therefore, it is central to reflect on the meaning and importance the childhood to bring about other perspectives and social practices, policies and economics for children, since this generational category is essential for the development of society.

Keywords: children; childhood; society.
\end{abstract}




\section{Considerações preliminares ${ }^{1}$}

A pergunta que constitui o título deste texto pode ser entendida como um paradoxo, na medida em que não é possível incluir algo que já está incluído. Mesmo assim, a discussão é necessária, pois nos leva a refletir sobre a peculiaridade da infância e a importância das crianças na sociedade.

Segundo a interpretação de John O'Neill (1997), as crianças não vão bem entre nós. São um tesouro e, ao mesmo tempo, um refugo. Imaginamos a infância de um modo distinto daquele existente. Além disso, destinamos para essa idade, caracterizada como sendo da inocência, todas as esperanças para o desenvolvimento da humanidade.

Entretanto, somente depositar esperanças sobre a infância não garante o desenvolvimento da sociedade e, tampouco, o do ser humano. É preciso muito mais; é preciso garantir que a infância e as crianças participem e que elas sejam consideradas como parte do conjunto da sociedade. Isso significa entender que qualquer decisão adotada no plano cultural, econômico, político e social - para citar algumas esferas - afetará a vida das crianças e, por conseguinte, o desenvolvimento atual e futuro da sociedade. Sabemos que "desenvolvimentos políticos e econômicos acontecem às nossas costas e ocorrem sem a devida consideração às crianças e à infância - não necessariamente por má vontade, mas simplesmente porque costumamos ver as crianças como um fenômeno altamente privatizado" (Qvortrup, 2010b, p. 791). Nesse caso, elas são primeiramente consideradas responsabilidade de um adulto - dos pais, por exemplo.

É preciso esclarecer que, quando ressaltamos a importância da participação da infância na sociedade, não queremos dizer que cada criança deva manifestar-se sobre questões que envolvam as esferas estruturais. Sabemos que as crianças precisam de proteção diante de sua vulnerabilidade natural, a qual é inerente à sua condição e diminui conforme elas crescem (Lansdown, 1994). Do mesmo modo, sabemos que as crianças atuam em diferentes âmbitos - por exemplo, família, escola, grupos de amigos e igreja - e os modificam a partir das relações e interações que estabelecem com os demais indivíduos. Trata-se, portanto, de um enfoque completamente diferente, ou seja, trata-se de considerar e refletir sobre como "os eventos, grandes e pequenos, terão repercussões sobre as crianças como parte da sociedade; e, em consequência, elas terão reivindicações a serem consideradas nas análises e nos debates acerca de qualquer questão social maior" (Qvortrup, 2011, p. 202).
1. Agradeço a Débora Perillo Samori as sugestões feitas em relação a este texto. 
Ainda que a passos lentos, reconhecemos que as crianças e a infância têm sido incluídas na agenda setting ${ }^{2}$ e que a comunidade científica ${ }^{3}$ está mais interessada por essa categoria ${ }^{4}$ para além do âmbito da escola e da família. Na compreensão de Berry Mayall (2007), existem três razões para esse interesse crescente sobre a infância: primeiramente, aprimorar o conceito relativo ao funcionamento da sociedade; em segundo lugar, construir uma justiça social para as crianças, e, em terceiro lugar, refletir sobre os fundamentos teóricos em relação aos serviços destinados a essa categoria. Entendemos, no entanto, que não foi a infância que se tornou mais interessante, mas a sociedade que começou a interessar-se por ela. "A isso, acrescente-se a inescrutabilidade do futuro, tanto no que diz respeito ao destino do indivíduo como ao destino global5" (Burckhardt, 1961, p. 18). Com razão, é o futuro que nos faz refletir sobre a infância e as crianças, pois ele não é apenas uma imagem, mas é real, na medida em que necessitamos ter a capacidade de prever eventos futuros e preparar-nos para as necessidades que virão (Cassirer, 1994).

Existem dificuldades, desinteresses e posições adultocêntricas ${ }^{6}$ que atravessam o debate sobre a participação da infância na sociedade, mas esse modesto movimento de atenção à categoria e a esses indivíduos ${ }^{7}$ já representa o começo de transformações. Assim sendo, este texto divide-se em três partes. Na primeira, será analisada a concepção de desenvolvimento para o campo da infância e seu significado quando são consideradas as crianças. Na segunda parte, serão discutidas e avaliadas as formas de participação, a função e os atributos da infância e das crianças. Por fim, na última parte, o objetivo é refletir acerca dos desafios existentes para integrar tal categoria à sociedade. As análises estarão notadamente fundamentadas no pensamento de Jens Qvortrup e de Giovanni Sgritta.

\section{As crianças, a infância e a concepção de desenvolvimento}

0 conceito de infância é complexo e amplo, pois abrange tanto as crianças que definem a categoria, como as representações e os conceitos científicos e do senso comum que estão presentes na sociedade. De acordo com o verbete escrito por Giovanni Sgritta (1994), as diversas acepções da palavra envolvem desde os assuntos relativos à higiene da criança até o seu desenvolvimento harmonioso a partir do campo da psicologia. Existe uma variedade de palavras para se referir à infância e às crianças - por exemplo, menoridade, infantil, imaturo, infância, criança, recém-nascido
2. Segundo Adilson Citelli (2000), existe um conjunto de informações que circulam na sociedade, as quais são indicadores fundamentais que orientam os indivíduos e suas avaliações acerca dos acontecimentos.

3. Atualmente, tanto a Associação Internacional de Sociologia (ISA) como a Associação Internacional de Sociólogos Franceses (AISLF) contam com comitês científicos e grupos de pesquisa específicos a respeito da infância.

4. A infância é considerada uma categoria geracional que compõe a estrutura social, a qual influencia a sociedade e é influenciada por ela. As demais categorias são juventude, idade adulta e velhice.

5. Jacob Burckhardt (1961) não faz referência à infância; seu propósito é compreender as intenções e percepções dos indivíduos em determinada época.

6. Adultocentrismo é a sociedade pensada e construída em torno do e para o adulto, ou seja, é a sociedade centrada no adulto (Rosemberg, 1976). Ademais, a concepção adultocêntrica considera as ações e atuações das crianças como algo natural.

7. Será utilizado aqui o conceito de indivíduo, compreendido como concreto e singular (Lahire, 2006). 
e bebê - que representam as diversas etapas do crescimento ou do desenvolvimento desses indivíduos, dificultando, assim, o esclarecimento dos termos e da categoria a partir do campo social (Sgritta, 1992). Uma vez que as análises de Giovanni Sgritta foram realizadas no início da década de 1990, época em que havia escassez de concepções sociológicas a respeito da infância e das crianças, pode-se dizer que já ocorreu um processo de mudança a esse respeito, na medida em que os estudos do campo sociológico passaram a tratar do tema.

Assim, a questão a ser tratada aqui parte de dois sentidos, a saber: o desenvolvimento das crianças e o desenvolvimento da infância. No primeiro caso, entende-se que a infância é uma fase da vida que reúne crianças, as quais passarão por diversos estágios de desenvolvimento e crescimento. Espera-se que elas cresçam e se desenvolvam dentro dos propósitos desejados pela sociedade - tanto científicos como do senso comum. Essa concepção compreende as ideias de desenvolvimento, proteção ${ }^{8}$ e socialização, isto é, considerando-se as perspectivas futuras, as crianças devem ser civilizadas, cuidadas e ensinadas a respeito do conjunto de regras e valores socioculturais. Portanto, o processo de formação das crianças deve ser composto por diferentes experiências - artísticas, corporais, lúdicas, verbais e cognitivas, por exemplo.

Não temos motivos para questionar a importância do desenvolvimento de cada criança, tampouco de sua socialização e proteção. Consideramos que, ao longo da vida, todos os indivíduos passam por processos de transformações psíquicas, emocionais, físicas e cognitivas. Além disso, em situações variadas, todos necessitam de cuidados e devem aprender sobre a sociedade e a cultura das quais participam. De acordo com esse sentido contemporâneo, a socialização não pode mais ser compreendida como unidirecional, mas deve ser pensada como relacional e interacional. A perspectiva relacional tem como eixo central "a participação do sujeito social em seu processo educativo" (Setton, 2009a, p. 297).

No decorrer da história, as circunstâncias e os contextos produzidos e vivenciados pelos e entre os indivíduos modificaram as relações sociais. A proteção das crianças passou a ter maior relevância e ser atribuída como responsabilidade da família e da escola. Dessa forma, a participação social das crianças ficou comprometida, pois elas ficaram reclusas em tais espaços. 0 fato é que essas instâncias socializadoras têm como objetivo a formação do indivíduo (sob uma perspectiva individualista) para o futuro
8. Certamente se trata uma proteção ambígua, pois são muitas as crianças que ainda sofrem abusos e maus tratos, por vezes ocorridos nos espaços familiar e escolar. 
(sob uma perspectiva evolutiva). Porém, quando se consideram apenas esses preceitos, esquece-se que as crianças participam de uma importante categoria geracional, que elas vivem o presente e que o desenvolvimento da categoria é fundamental tanto para o momento atual como para o futuro.

É no presente que as crianças participam, atuam, relacionamse e interagem com outros indivíduos. É também no tempo presente que elas vivem os infortúnios e as prosperidades de seu cotidiano. Em razão disso, as análises a respeito da infância e do desenvolvimento das crianças devem atentar para suas circunstâncias e seus contextos de vida na atualidade, para, então, confrontá-los criticamente com os desejos futuros, mas considerando os acontecimentos do passado. A infância é uma categoria que constitui a sociedade; portanto, ela é atual e sempre existirá.

Contudo, em razão das condições de proteção, socialização e desenvolvimento infantil consideradas a partir de uma perspectiva unidirecional e gradual, a infância e as crianças têm poder de atuação restritos e isso as configura como secundárias no conjunto da sociedade. Sendo assim, a confrontação crítica, mencionada anteriormente, deve ser realizada com as demais categorias geracionais e é necessária para produzir transformações em um sentido de progresso. Esse sentido é entendido a partir de Theodor Adorno (1992), que esclarece que "o conceito de progresso é filosófico na sua capacidade de contrapor-se ao movimento da sociedade no passo mesmo em que o articula. Derivado da sociedade, ele reclama a confrontação crítica com a sociedade real" (p. 223).

É esse embate crítico articulado às reais condições de vida das crianças e à função da infância na sociedade que deve ser realizado, pois muitas das propostas políticas ou econômicas, por exemplo, não as consideram e são dirigidas para as instituições familiar e escolar. Da mesma forma, quando o Estado planeja cortes orçamentários, mudanças na previdência social ou qualquer outra alteração política ou econômica, os dirigentes não ponderam de que forma isso vai repercutir na infância. Quando a taxa de desemprego aumenta, não se questiona de que modo isso afetará a vida das crianças. Poderíamos dar outros exemplos, mas o que se quer demonstrar é que, quaisquer que sejam as propostas, ainda são poucas aquelas direcionadas para a categoria da infância.

Entendemos que as propostas que a sociedade formula podem repercutir diretamente sobre as crianças. Para citar um 
exemplo, cabe pensar "se as crianças - dada a sua condição de não votantes - têm uma representação política adequada" (Qvortrup, 2010b, p. 782). Certamente não, pois elas não votam; são seus pais que votam, e, se eles as consideram, é a partir dos interesses familiares. Em outra perspectiva, mesmo que os pais considerassem os interesses das crianças, ainda assim elas seriam representadas por uma pequena parcela de adultos que têm filhos (Qvortrup, 2010b). É nesse sentido que podemos afirmar que as crianças são cidadãs secundárias e igualmente vulneráveis em razão das falhas do poder e dos direitos políticos, econômicos e civis relacionados a elas.

Trata-se de uma vulnerabilidade estrutural decorrente de uma construção histórica, social e política, bem como de presunções a respeito da natureza da infância. A relação entre vulnerabilidade inerente e estrutural é estabelecida por atitudes culturais (Lansdown, 1994). Nesse sentido, os meios, os recursos, as influências e o poder são distribuídos de maneira desigual entre as categorias geracionais, cujas habilidades para enfrentar os desafios externos são diferentes (Qvortrup, 2010a; Sgritta; Saporiti, 1989).

Como cidadãs secundárias, as crianças somente têm seus direitos assegurados por meio de um responsável vinculado a elas; na maioria dos casos, os responsáveis são os pais. De um lado, os direitos estabelecidos pelos adultos às crianças retornam para elas, em geral, por meio da família e/ou da escola. De outro lado, se lhes é concedida alguma autonomia, esta depende da definição estabelecida pelos adultos. Portanto, a condição dada para a infância e as exigências impostas às crianças definem-nas como secundárias na estrutura social, pois, se elas fossem a unidade de observação, seriam constituídas outras práticas e outros discursos para a infância e para as crianças (Sgritta, 1994).

Tal análise leva-nos à segunda acepção, ou seja, o desenvolvimento da infância. A infância é permanente na sociedade, mas não se configura sempre do mesmo modo. Se compararmos a infância ao longo da história, é possível perceber as transformações e as continuidades ocorridas na categoria (Qvortrup, 2010a; 2001). Uma das mudanças representativas para a infância, e que incidiu sobre a vida das crianças, foi a entrada das mulheres no mercado de trabalho. 
muitos, embora não se tenha tanta certeza disso. De todo modo, foi um desenvolvimento que teve um enorme impacto na infância e na vida das crianças. Em muitos países, foi acompanhado da criação de jardins de infância, creches, centros de atendimento para depois do horário escolar etc., onde as crianças são obrigadas a passar grande parte de sua infância. Esse é um exemplo de política que visa deliberadamente a infância, embora, em um primeiro momento, a entrada das mulheres no mercado de trabalho não incluísse uma preocupação com as crianças ou a infância; ela se tornou necessária em um segundo momento (Qvortrup, 2010b, p. 784).

A participação e a inserção da infância no campo social envolvem modificações no modo de perceber esses indivíduos, suas relações com a sociedade, com as práticas e as ideias acerca da categoria. Assim, entendemos que as crianças são atores sociais atuantes e fundamentais para o desenvolvimento da vida cotidiana. Portanto, o desenvolvimento da infância está intrinsecamente vinculado à estrutura macro da sociedade e às atuações das crianças nos espaços dos quais participam, pois qualquer mudança realizada nas diferentes esferas que compõem a estrutura social - economia, política, tecnologia, cultura, ideologia e educação, para citar algumas delas - afetará não só a vida contemporânea e o futuro delas, como também toda a sociedade. Por essas razões, entendemos que indivíduos, categorias e instituições formam um todo - complexo -, portanto não podem ser separados e devem ser considerados em conjunto.

\section{A participação, a função e os atributos da infância e das crianças}

É importante definir, primeiramente, que a infância é uma categoria estrutural na sociedade. A ideia de estrutura rompe com o plano de vida pessoal, com a concepção de fase da vida e nos "faz pensar não em termos do desenvolvimento da criança, mas, particularmente, no desenvolvimento da infância" (Qvortrup, 2010b, p. 635, grifos do autor). Nesse sentido, a categoria da infância é constituída por um conjunto de parâmetros:

\footnotetext{
[...] estamos falando de parâmetros econômicos, políticos, sociais, culturais, e tecnológicos, e certamente temos em mente também os parâmetros ideológicos e discursivos, ou seja, parâmetros que representam os entendimentos e as ideologias sobre as crianças e a infância. É a interação entre os parâmetros que produz todas as configurações sociais, incluindo os grupos sociais e as relações entre eles (p. 636-637).
}

Como já foi mencionado, e considerando o desenvolvimento das crianças, há uma perspectiva estabelecida socialmente que 
entende que elas devem desenvolver-se e ir da imaturidade à maturidade. Porém, será que a infância também deve desenvolverse dessa mesma forma? Obviamente, os dois casos são complexos e fundamentalmente diferentes. De modo geral, enquanto, no primeiro caso, a ideia principal vincula-se ao período de vida, no segundo, a infância é um fato que é parte da estrutura social.

Quando se diz que as crianças devem desenvolver-se e que elas são imaturas, parte-se de uma comparação com o modelo adulto. Essas diferenças são estabelecidas a partir da oposição de atributos positivos e negativos. Nesse caso, se elas são consideradas fracas, irracionais e incapazes, os adultos são fortes, racionais e competentes. Contudo, se porventura os adultos forem corrompidos e tiverem tendências contrárias à moral estabelecida pela sociedade, então as crianças tornar-se-ão símbolo da inocência, da criatividade e da redenção social (Sgritta, 1992; La Palombara, 2001).

Outros atributos determinados para as crianças e a infância são o hedonismo e o lúdico. A categoria geracional da infância usufruiria de algumas manifestações, como a fantasia, o ócio, o tempo livre e a tranquilidade. Na contraposição dessas ideias, estariam o trabalho, a responsabilidade e a realidade, todos esses elementos vinculados ao mundo adulto. Para a antropóloga Ruth Benedict (2009), tais posições e oposições são dogmas culturais de nossa cultura que definem as condições sociais para todos os indivíduos, mas que não são necessariamente aceitos por outras culturas.

Essa forma de interpretação está pautada em imagens e discursos acerca de percepções típicas e ideais. Portanto, entendemos que o conhecimento sobre a infância e as crianças ainda encontra-se mais próximo de um pensamento mágico metafísico do que de um pensamento científico interpretativo (Elias, 2008). De todo modo, deve-se ponderar que para participar da sociedade não é condição obrigatória ser competente ou experiente (Qvortrup, 2011). Com razão, os indivíduos, sejam eles crianças ou adultos, são diferentes e têm interesses diversos. Essa forma de construção é assim organizada devido a conceitos e práticas culturais. Ademais, as diferenças entre adultos e crianças, ou entre a infância e a idade adulta, geraram um distanciamento necessário para a constituição das categorias e das identidades individuais. Desse modo, o que realmente há são participações, interações e experiências diferenciadas que levam cada um a desenvolver-se a partir de condições bio-sócio-culturais ${ }^{9}$. A participação das crianças na sociedade garante continuidade à 
tradição e às produções humanas porque os indivíduos socializamse e porque há o legado cultural como fundamento. É a partir de relações e interações diversas que acontecem as transformações, e aí está, portanto, a capacidade da sociedade em renovar-se constantemente.

Mesmo assim, quando pensamos sobre qual é a função das crianças na sociedade, deparamo-nos com a ideia de desenvolvimento do indivíduo e esquecemos que todos são atores sociais. Também perdemos de vista a categoria e tentamos compreender um único indivíduo, com atenção ao seu comportamento, ao seu futuro e às suas atividades. Esse modo de procedimento pode levar-nos a supor certa passividade infantil, ou seja, como se as crianças não interviessem em seu meio e tempo sociocultural. A interpretação de Roger Bastide (2004) é provocadora ao tratar da relação dos adultos com as crianças:

\footnotetext{
Que somos nós, para as crianças que brincam ao nosso redor, senão sombras? Elas nos cercam, chocam contra nós; respondem às nossas perguntas, num tom de condescendência, quando fingimos interessar-nos por suas atividades; mas sente-se, perfeitamente, que, para elas, somos como os móveis da casa, parte do cosmos exterior, não pertencemos a seu mundo, que tem seus prazeres e seus sofrimentos. E nós, adultos, vivemos também dentro de nossas próprias fronteiras, olhamos as crianças brincar, repreendemo-las quando fazem muito barulho, ou, se deixamos cair sobre seus divertimentos um olhar amigo, não é para eles que olhamos, mas, através deles, para as imagens nostálgicas de nossa infância desaparecida (p. 229).
}

É preciso esclarecer que, ao dizer que as crianças são atores sociais, compreende-se que o ator é agente do ato e autor de suas palavras (Arendt, 1987). Todo ator social tem uma história e propriedades que indicam seus interesses e princípios constituídos a partir de trocas coletivas. Portanto, os atores têm ações criativas, moldam continuamente a realidade por meio das decisões que tomam e das atitudes que adotam a partir das interações que estabelecem (Giddens, 2005). Dessa forma, é verdadeira a afirmação de que as crianças desempenham atividades importantes nos espaços onde podem participar, ou seja, na família e na escola.

A questão é que os ofícios das crianças não são valorizados pela sociedade. Em decorrência de sua vulnerabilidade inerente, a sociedade imagina uma infância, acredita que ela não trabalha e que é protegida pela família e pela escola. Porém, essa proteção não é efetiva e, em decorrência da vulnerabilidade estrutural, a 
infância fica oculta na sociedade. São as atitudes socioculturais que determinam o que as crianças podem ou não fazer, mesmo nos espaços organizados para elas. Por exemplo, a ajuda doméstica infantil tem valor na medida em que as ações das crianças geram benefício para os demais envolvidos (Edmonds; Pavcnik, 2005). Decerto, trata-se de um trabalhado diferenciado, pois depende de algumas variáveis: se se nasce menino ou menina, rico ou pobre; da etnia e da raça a que se pertence; da cultura da qual se participa. Já ir à escola é uma função gerida pelo Estado. É um trabalho permanentemente realizado sob um novo sistema, o escolar, atribuído ao Estado como economia relevante, mas que não remunera e tampouco considera as crianças como participantes do tecido social (Qvortrup, 2010c, 2001).

A escola é um direito das crianças, mas é também um dever delas e um ofício da infância. A escola é trabalho, é um trabalho intelectual que representa uma continuidade histórica de desempenho em relação às atividades obrigatórias impostas por qualquer economia vigente (Qvortrup, 2010c). Assim, qualquer economia dominante precisa desse trabalho infantil imanente ao sistema, uma vez que as gerações estão atreladas em função da manutenção das aposentadorias e do desenvolvimento social. Essa afirmação indica um contrato geracional, no qual cada geração tem um papel basilar para cumprir (Qvortrup, 2010c).

Outra questão a ser considerada sobre o trabalho escolar é seu caráter intelectual, pois ler, escrever, contar e dominar algumas tecnologia são disposições básicas e necessárias para o mercado de trabalho. Ademais, são as gerações mais novas que darão continuidade ao movimento do desenvolvimento tecnológico (Qvortrup, 2010c). Desse modo, o que precisa mudar é a forma como a sociedade entende a educação: deve-se passar a considerá-la como uma atividade fundamental que se vincula à estrutura e mantém o desenvolvimento social, envolvendo, portanto, todos os indivíduos. Com base nas análises realizadas até aqui, o desenvolvimento da infância está em estreita ligação com o desenvolvimento da sociedade, pois as mudanças nas disposições do complexo social irão acarretar transformações tanto para essa categoria geracional como para as demais - juventude, idade adulta e velhice. 


\section{Os desafios para o desenvolvimento da infância}

Feita essa apreciação, entendemos que é possível recompor os principais argumentos aqui desenvolvidos. Para iniciar, consideramos que a pergunta que inaugura esse texto - É necessário integrar as crianças à sociedade? - é uma quimera. Entendemos dessa forma, pois as crianças nascem em uma sociedade, estão nessa sociedade e são parte dela. Por sua vez, a infância é uma categoria geracional fundamental para a estrutura social e estabelece relações com as demais categorias. Assim, a perspectiva que desenvolvemos ao longo do texto avalia como imprescindíveis as funções, os atributos e as atuações das crianças e da infância para a reprodução e a produção de valores, normas, práticas e ideias.

Todavia, se as crianças e a infância têm valor social, econômico e cultural, este é ainda pouco reconhecido socialmente. Mas é ele que ajuda a definir as condições, funções e atribuições das categorias e dos indivíduos. Por exemplo, no caso da infância, os adultos entendem que as crianças necessitam de proteção para chegarem à maturidade; porém, tal proteção anula a participação delas nos diferentes âmbitos da sociedade. Essa não é uma questão simples e podemos pensá-la de duas maneiras:

\footnotetext{
[...] deveríamos fazer de tudo para proteger as crianças ao preço de deixálas fora da "sociedade" ou deveríamos reconhecê-las como pessoas, participantes, cidadãs com o risco de expô-las às forças econômicas, políticas e sexuais [...]? [...]. De fato, ninguém está disposto a sacrificar a necessária proteção das crianças expondo-as a todos os riscos de uma sociedade moderna; porém, ninguém concordaria em privar as crianças de se experimentarem como pessoas que contribuem para a sociedade (Qvortrup, 2010b, p. 779).
}

A proteção e a participação são preceitos com sentidos diferentes que precisam ser equilibrados quando se trata das crianças e da infância. Entendemos que a resposta a essa questão esteja em uma mudança de olhar e de atitudes dos adultos, velhos e jovens em relação à socialização e ao desenvolvimento das crianças e da infância. Em outras palavras, a socialização e o desenvolvimento precisam ser compreendidos como processos que envolvem todos os indivíduos. No caso da socialização, ela é parte de 
enfatizar as estratégias de transmissão e, portanto, de transformação dos valores dos grupos sociais, além de examinar as disposições de cultura incorporadas pelos indivíduos ao longo de suas experiências de vida (Setton, 2009b, p. 17).

A socialização não é uma via de mão única, mas um processo de interação que abrange a todos; portanto, é um processo no qual as pessoas atuam em conjunto. Mesmo na escola e na família, é interagindo que as pessoas aprendem, modificam suas ideias, questionam, criticam, adaptam-se e, enfim, configuram diferentes relações conforme as circunstâncias e o contexto. Essas configurações são como uma dança de salão.

\footnotetext{
Certamente podemos falar na dança em termos gerais, mas ninguém a imaginará como uma estrutura fora dos indivíduos ou como uma mera abstração. As mesmas configurações podem certamente ser dançadas por diferentes pessoas, mas, sem uma pluralidade de indivíduos reciprocamente orientados e dependentes, não há dança (Elias, 1994, p. 249-250).
}

Nesse caminho, consideramos que o desenvolvimento das crianças é importante, mas precisa abranger outros entendimentos sociológicos, políticos e antropológicos, por exemplo. 0 desenvolvimento das crianças ocorre a partir da combinação de diferentes fatores sociais, biológicos e culturais. É um processo no qual o que importa é o indivíduo atual e suas relações, ou, segundo a recomendação de Jens Qvotrup (2010b), "nosso objetivo não mudou: queremos ainda produzir um adulto melhor. A nova versão tem a vantagem de estabelecer uma situação melhor para todos: as crianças devem ser felizes enquanto se desenvolvem para se tornarem adultos ideais" (p. 788). Essas relações devem estar entrelaçadas com o desenvolvimento da infância. Segundo Giovanni Sgritta (1992), para entendermos esse outro desenvolvimento da infância, devemos considerar a categoria geracional e sua relação de importância com as demais categorias, pois é a partir desse conhecimento que será possível criar mecanismos valorativos para a infância. Também devemos retirar as crianças da margem social e compreender a infância como um segmento estrutural da sociedade.

Como último argumento, entendemos que, se as crianças são importantes para o futuro, as mudanças em relação à infância devem começar agora, com o reconhecimento de suas funções na escola e na família. É por meio dessas instituições que as crianças participam da sociedade, e, assim sendo, sua valorização deve começar pelos pais e professores. Isso significa fazer com que elas realmente participem, organizem e avaliem as práticas que 
envolvem seu próprio cotidiano nessas instâncias. Além disso, mudanças na estrutura macro podem começar a despontar, por exemplo, o planejamento de propostas e estudos sobre como as crianças são afetadas em decorrência de mudanças na estrutura da sociedade - considerando-se os pontos positivos e negativos.

Dessa forma, com o presente texto, procuramos iniciar uma discussão a respeito da importância da participação das crianças e da infância no amplo cenário social, econômico, político e cultural. Trata-se de uma análise que, em um primeiro momento, pode parecer utópica, pois considera as crianças como sujeitos políticos ${ }^{10}$, mas é um debate necessário para o desenvolvimento da sociedade contemporânea. Ademais, acreditamos na possibilidade de mudanças, na possibilidade de inserir os assuntos aqui tratados sobre a infância e a participação das crianças na pauta das discussões dos interesses públicos e privados.

\section{REFERÊNCIAS}

ADORNO, Theodor W. Progresso. Lua Nova, São Paulo, v. 27, dez. 1992.

ARENDT, Hannah. A condição humana. Rio de Janeiro: Forense-Universitária, 1987.

BASTIDE, Roger. Prefácio. In: FERNANDES, Florestan. As "trocinhas" do Bom Retiro: contribuição ao estudo folclórico e sociológico da cultura e dos grupos infantis. Pro-posições, Campinas, v. 15, n. 43, jan./abr. 2004.

BENEDICT, Ruth. Continuità e descontinuità nel condizionamento culturale. In: LENINE, Robert; NEW, Rebeca. Antropologia e infanzia. Sviluppo, cura, educazione: studi classici e contemporanei. Milano: Raffaello Corina Editore, 2009.

BURCKHARDT, Jacob. Reflexões sobre a história. Rio de Janeiro: Zahar Editores, 1961.

CASSIRER, Ernst. Ensaios sobre o homem: introdução a uma filosofia da cultura humana. São Paulo: Martins Fontes, 1994. movimento. São Paulo: SENAC, 2000. 
EDMONDS, Eric V.; PAVCNIK, Nina. Child labor in the global economy. Journal of Economic Perspectives, v. 19, n. 1, 2005.

ELIAS, Norbert. O processo civilizador. v. 1. São Paulo: Summus, 1994 Introdução à sociologia. Lisboa: Edições 70, 2008.

GIDDENS, Anthony. Mundo em descontrole. Rio de Janeiro: Record, 2005.

LAHIRE, Bernard. A cultura dos indivíduos. Porto Alegre: Artmed, 2006.

LA PALOMBARA, Alessandro. Cultura dell'infanzia e comunicazione tra bambini. Tese (Doutorado em Sociologia dos Fenômenos Culturais e dos Processos Normativos, XIII Ciclo) - Faculdade de Sociologia, Universidade de Urbino, Urbino, 2001

LANSDOWN, Gerison. Children's rights. In: MAYALL, Berry (Ed.). Children's childhoods: observed \& experienced. London: The Falmer Press, 1994.

MANNHEIM, Karl. El problema de las generaciones. Revista Española de Investigaciones Sociológicas - Reis, Madrid, n. 62, abr./jun. 1993.

MAUSS, Marcel. Sociologia e antropologia. São Paulo: Cosac\&Naify, 2003.

MAYALL, Berry. Sociologies de l'enfance. In: BROUGÈRE, Gilles; VANDENBROECK, Michel (Dir.). Repenser l'education des jeunes enfantes. Bruxelles: P.I.E Peter Lang, 2007.

O'NEILL, John. Is the child a politic subjetc? Childhood, Sage Publications, v. 4, n. 2, May, 1997.

QVORTRUP, Jens. O trabalho escolar infantil tem valor? A colonização das crianças pelo trabalho escolar. In: CASTRO, Lúcia Rabello de (Org.). Crianças e jovens na construção da cultura. Rio de Janeiro: NAU Editora/ FAPERJ, 2001.

A infância enquanto categoria estrutural. Educação e Pesquisa, São Paulo, v. 36, n. 2, maio/ago. 2010a. 
Infância e política. Cadernos de Pesquisa, São Paulo, v. 40, n. 141, set./dez. 2010b.

Trazer de volta o papel da criança no contrato geracional. In: REUNIÃO ANUAL DA ANPED, 33., 2010, Caxambu. Sessão especial GT 14. Educação na infância: perspectivas históricas, sociológicas e políticas. Tradução de Maria Letícia B. P. Nascimento. Caxambu, 2010c.

Nove teses sobre a "infância como um fenômeno social". Pro-posições, Campinas, v. 22, n. 1, jan./abr. 2011.

ROSEMBERG, Fúlvia. Educação para quem? Ciência e Cultura, SBPC, v. 28, n. 12, dez. 1976.

SETTON, Maria da Graça Jacintho. A socialização como fato social total: notas introdutórias sobre a teoria dos habitus. Revista Brasileira de Educação, Rio de Janeiro, v. 14, n. 41, maio/ago. 2009a.

A socialização como fato social total: um ensaio sobre a teoria do habitus. Tese (Livre-Docência) - Faculdade de Educação, Universidade de São Paulo, São Paulo, 2009b.

SGRITTA, Giovanni B. Infanzia: una generazione a perdere? In: CARMINATI, Valeria Longo; COSTANTINO, Domenico (a cura di). Essere bambini oggi. Estratto. Milano: Vita e Pensiero, 1992. Infanzia. In: Estratto dal Volume IV della Enciclopedia delle Scienze Social. Istituto della Enciclopedia Italiana. Fondata da Giovanni Treccani, 1994.

SGRITTA, Giovanni B.; SAPORITI, Angelo. Childhood as a social phenomenon: implication for future social policy. International comparative research project. National Research Council. Country Report 1989/13. Italy, June 1989.

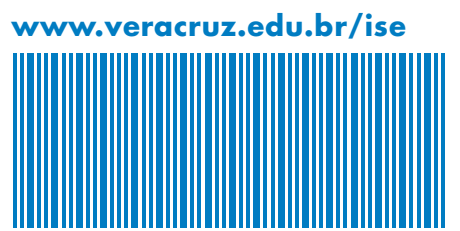

